\title{
Construction of Enterprise Credit System against the Backdrop of Big Data
}

\author{
Siqi Li \\ School of Finance \\ Guizhou University of Finance and Economics \\ Guiyang Guizhou, China \\ 546932209@qq.com
}

\author{
Mu Zhang* \\ School of Finance \\ Guizhou University of Finance and Economics \\ Guiyang Guizhou, China \\ rim_007@163.com \\ *Corresponding author
}

\begin{abstract}
In order to improve the level of enterprise credit information service, promote the enterprise credit system construction process and realize the enterprise credit information sharing, this paper, based on the construction practice of existing enterprise credit information database, tentatively puts forward enterprise big data general principles and methods of the credit system construction. This paper absorbs experience of enterprise credit system construction at home and abroad, analyzes the big data problems against the backdrop of the construction of enterprise credit system and its main reasons put forward the thinking of perfecting the enterprise credit system construction. According to the actual situation of the development of China's enterprise credit system, the improvement of the credit system of China's enterprises mainly starts from information acquisition and evaluation system construction. This paper sums up the basic content of enterprise credit system construction and emphasizes the importance of perfect enterprise credit culture system construction.
\end{abstract}

Keywords-Big data; Enterprise credit information; Credit system; Application

\section{INTRODUCTION}

"Big data" refers to the data set, which is a large number, numerous types, complex structure, and a certain number of data. Big data technology has high application value and business value ${ }^{[1]}$. Big data technology has wide application prospect and great commercial value. At present, the social from all walks of life through integration of large data sharing and the cross application, has developed the data warehouse, data analysis and practical technology, such as data mining, to form a powerful intellectual resources and knowledge service ability. Our country has also led or participated in the construction of credit information database of many local enterprises, with strong data concepts and big data application capabilities. To realize the full application of domestic and foreign enterprises large data, this paper, on the basis of the existing enterprise credit database construction, discusses the general principles of big data applications, further improve the level of enterprise services, and effectively promote the process of enterprise credit system construction.

This work was financially supported by National Natural Science Foundation of China (71263011).

\section{The Present SituAtion AND EXISTING Problems OF ENTERPRISE CREDIT SYSTEM CONSTRUCTION}

\section{A. The present situation of enterprise credit system construction}

In July 2014, the state council promulgated the program for the construction of social credit system, points out that although we have made some progress in the construction of our social credit system, the contradictions that are incompatible with the level of economic development and the stages of social development are uncoordinated and not suited $^{[2]}$. The current situation of corporate credit in China shown as follows:

1) China's enterprise credit system is mainly led by the people's bank, which was divided into three levels: municipal, provincial and bank in 1997. Since then, departments of industry, commerce, taxation, customs, banking, public security, courts and insurance departments have gradually established their own database systems to record the relevant information of enterprises. However, information databases between departments are not integrated, and their information is not connected to form an island of information ${ }^{[3]}$.

2) The credit record of all members of the society is severely lacking, so it is impossible to motivate the faithful and punish the person who lost their faith.

3) Enterprise credit information is not complete, credit service market is not developed, service system is not mature, the service behavior is not standard, service credibility is insufficient, healthy protection mechanism of the main rights of credit information is to be built .

\section{B. Problems existing in the construction of enterprise credit system}

With the rise of big data, and so on technology, the emerging business mode in the rapid development of our country, such as the Internet financial market to the requirement of increasing the enterprise credit system, exposes the problems existing in the credit system gradually. The enterprise credit system of our country provides the convenient channel for enterprise financing to some extent, solves the capital needed for enterprise development and promotes enterprise development. Some achievements have been made at the same time. Some problems still exist, which include: 


\section{1) Data segmentation is serious}

Our government departments respectively control the enterprise all kinds of professional data information, such as the ministry of commerce and industry have industrial and commercial registration of the enterprise and the registration information, the labor department of social security enterprise social security, labor data and so on. However, these data are only used by departments themselves, and are not shared with other departments and credit bureaus, resulting in these data not being more efficient for enterprise credit evaluation services. Duplication of data in all departments can result in a great waste of administrative resources ${ }^{[4]}$.

2) Credit information is incomplete and sources are narrow

At present, the enterprise credit information of the people's bank of China is mainly from commercial banks, rural credit cooperatives, small loan companies and other specialized agencies that provide credit services. Government-led regional credit agencies only provide basic information to industrial and commercial registration, objectively collect and display our customers' basic information, do not give any comments to the customer credit information. Private credit companies have narrow information channels, limiting the further deepening of credit products.

\section{3) Small and micro enterprise data is lacking}

The important reason for the current financing difficulty of small and micro enterprises is the information asymmetry. To solve this problem, small and micro enterprise credit information system should be established and credit rating ${ }^{[5]}$. At present, our country small micro enterprise credit data obtained from public channels is very hard, although available from government department, but the database also contains only data of large and medium scale enterprises, no small enterprise data, seriously hindered the development of data collection using credit.

\section{4) Risk assessment management method is not scientific}

There are many problems in the construction of corporate credit information system in China, such as the analysis of the industry level, the analysis of the degree of repayment willingness and the complexity of the index system. Perfect credit rating system should include data description, data analysis, model development, credit rating and other levels, that gradually reflect the enterprise's comprehensive credit status. The more complete credit evaluation system should have data analysis, data description, credit rating, model development and so on, so as to reflect the enterprise's comprehensive real credit situation gradually ${ }^{[6]}$.

5) Excessive competition among credit rating agencies

The situation of excessive competition exists in many kinds of credit rating agencies in China, which has a great negative impact on the development of the credit collection industry. With the help of broader coverage data and the more comprehensive dimension, the construction of enterprise credit information system which is induced by big data can well solve the problems that the traditional enterprise credit information system faces.

\section{The Application VAlue of Big Data Technology in ENTERPRISE CREDIT SYSTEM CONSTRUCTION}

In July 2014, the European Union called on member states to develop large data, also gave great importance to China, industry and academia for big data research and application of national "973 project", "863 project" and the national natural science funds are set up separately for big data research and special plans. Thus, the arrival of "big data era" will bring great positive influence and dividends to our society and Provide strong support for the credit system construction of enterprises $^{[7]}$.

\section{A. Big data technology is beneficial to the collection of corporate credit data}

Big data, also known as huge amounts of data, refers to massive, high-growth and diversified information assets that require new processing models to have stronger decisionmaking power and insight into discovery power and process optimization capabilities. Big data has remarkable characteristics such as large capacity, high value, fast speed and variety of types. Big data technology is the core value lies in it to mass data storage and analysis, we can use technology to establish an enterprise credit data system that gathers information of all enterprises in the country. This will help to solve the problem of incomplete credit information of enterprise credit information scattered and incomplete, so as to promote the good development of corporate credit.

\section{B. Big data technology is beneficial to enterprise credit data consolidation analysis}

The development of big data technology has gone from simple data communication and information transmission to targeted analysis based on massive data. We can quickly collect all the relevant information data from the enterprise through the Internet, and carry out information cleaning and analysis through big data technology. Then, using the most advanced information technology, the government and enterprises, enterprises and enterprises and individuals' activities information are recorded and collected together to analyze the information of enterprises, thus making the most complete, objective and credible credit evaluation. Now, we can judge from the data platform analysis of the flow of people, logistics and capital flows that the data published by a listed company is credible. Now, from the flow of people, logistics, capital flow analysis of the data platform can determine whether a listed company's data released is credible.

\section{Big data technology is beneficial to corporate credit supervision}

In China, the government departments are in charge of the construction and management of the enterprise credit information public display system, the financial information database, etc. They are formed by the industry association, management software and information service enterprise credit evaluation system and enterprise credit information management system. However, the objective facts of the serious lack of credit records of members of the society make it impossible for the current government departments or other institutions in the society to fully understand the credit information of the enterprises and therefore can't effectively 
supervise them. At this time, we can use big data technology for effective regulation to the enterprise credit.

\section{Big data technology is beneficial to enterprise financing}

Market failure theory holds that information asymmetry is one of the main causes of enterprise financing difficulties ${ }^{[8]}$. However, enterprises can integrate all kinds of big data to reflect the status of enterprise credit information, accurate reduction enterprise actual operation situation, create high efficiency, low cost, value rediscovery of enterprise financing market. The application value of big data technology in enterprises is mainly manifested in the following three aspects: it is beneficial to improve the financing efficiency, and it is beneficial to reduce the cost of financing, and is beneficial to the detection of potential value.

\section{The Application of Big Data TeChNOLOGY IN ENTERPRISE CREDIT DATA PLATFORM CONSTRUCTION}

Enterprise credit system construction is a complex system project. In the era of "Internet +", it is necessary to set up a central government, local governments at all levels, industry associations and enterprises to participate the construction of enterprise credit data platform, using big data technology to provide social enterprise credit data collection, analysis, evaluation and consultation. In this way, we can effectively solve the problems of the present enterprise credit data, which can't solve all the data collection and integration by the government departments at all levels or the industry and enterprises themselves. At the same time, it can also solve the principle of independence, objectivity, consistency, prudence and transparency and information disclosure in the enterprise credit system.

\section{A. Enterprise credit data collection and integration}

\section{1) Establish the enterprise credit unified data standard}

The construction of enterprise credit big data platform needs to integrate all over the country, departments, industry associations and enterprise credit information database, it must establish a unified enterprise credit data standards, clear each department data exchange directory and the unified metadata definitions. This can create favorable conditions for future data exchange to achieve national networking. If there is no a unified standard of data, then the local enterprise credit system can only be established by limited somewhere within the scope of information sharing, unable to join the national enterprise credit data platform, and negatively affecting the country's enterprise credit system.

\section{2) Thick data sampling survey}

Integration of data from the government department has the characteristics of "big data", the coverage of the enterprises, but fewer information item classes, is a kind of "thin data", failed to include all dimensions of an enterprise, types of information is not comprehensive, small scale of enterprises is not included. Thick data refers to a large number of data in a large number of information dimensions. The data can be obtained by sampling the enterprises. The survey of thick data is the main object of small and micro enterprises, as an important supplement to big data. If you can combine thick data with big data, it can't only reflect the past situation of the enterprise, but also predict the growth and risk of the future.

\section{3) Network data acquisition}

Although the data of various government departments and small micro enterprise sample survey data has multiple dimensions reflecting $s$ the enterprise credit information, but there are still many scattered data in all kinds of media, especially the Internet, such as reporting data of sampling observation of quality inspection departments, news media exposure data, online trading data, network, borrowing, etc. These data variables are rich and time-sensitive, and reflect the objective reality, which is a useful supplement to enterprise credit data. If the enterprise database can be included in time, the timeliness and comprehensiveness of corporate credit information will be greatly improved. Internet data can be automatically obtained by means of technology such as crawler technology to summarize the data obtained.

\section{4) Cross-departmental data integration}

Data integration can rely on local administrative forces to open up departmental barriers, and submit departmental data to specialized data processing agencies in the form of existing storage methods. Due to the different data structure of each department, the data of the departments should be cleaned and manually cleaned by professional data processing agencies to make a unified data reading format. In the data match, the main query coding based on the data of various government departments is not unified. For example, industrial and commercial departments mainly conduct data enquiries according to the commercial registration Numbers, and the tax departments mainly conduct inquiries according to the tax registration number ${ }^{[9]}$. But most department data contains the organization code, and the organization code is most associated with government information, so the organization code can be used as the main matching code.

\section{B. Construction of enterprise credit data platforms}

\section{1) Construction of enterprise credit data platform}

The important basis of enterprise credit data platform construction is to build a local enterprise credit information platform with complete information. Nationwide network of domestic all need credit systems at all levels and industry association credit information management system, all kinds of database import into the enterprise credit data platform, which already can reduce information brings security problems and solve the problem of enterprise credit data sources.

\section{2) Establish a unified enterprise credit data platform}

The integration of enterprise credit big data platform needs an independent and secure network operating environment. In accordance with the unified national enterprise credit data standards, we need rely on trusted national network resources to establish an independent network operating environment. In order to ensure the safe operation of the system, network security isolation with other systems is generally implemented through technologies such as firewalls, gateways and secure endpoints to ensure the independence and security among the systems. For business-generated network communication between, the authorization settings should be established to ensure security, as well as a stable and reliable independent database. 


\section{Enterprise credit evaluation system construction}

1) Establish five dimensional enterprise credit evaluation index

With the use of the Internet, enterprise's economic activities tracking will be automatically recorded. When the accumulation of corporate credit activity data reaches a large enough time, we can make the most objective and timely corporate credit rating. I think it is necessary to use big data technology to establish a five-dimensional corporate credit rating system. We should credit evaluation of enterprises, based on five dimensions, and use big data technology analysis of all external and internal activities, so as to make the most complete, the most objective and timely credit rating. We can evaluate enterprise credit through five dimensions: government's credit evaluation index for enterprises; Financial institutions' credit evaluation indicators for enterprises; The industry big data technology through the analysis includes the enterprise to the supply chain upstream and downstream enterprise's various transactions, accounts receivable accounts and so on dynamic information; The credit evaluation index for the main staff inside the enterprise; Enterprise consumer's credit evaluation index of enterprise ${ }^{[10]}$.

\section{2) Data mining and credit model development}

Through cross-departmental data integration, thick data sampling and network data, we collected data from three different sources to form a large database. Huge database contains a large amount of information related to enterprise credit conditions, also there might be some useless information, that must be through the directional data mining techniques to classify all kinds of data filtering, and integration, and high correlation with the enterprise credit status of the filtered data, provides the high accuracy of the data for the credit evaluation. For the enterprise credit system, through the study and application of a variety of methods, not only the accuracy of the enterprise credit risk evaluation can be improved, but also some more flexible credit products can be developed, in line with the practical application.

3) Establish a unified enterprise credit identification system

Credit rating system refers to the enterprise to meet the market demand for high-quality credit information, by a certain qualification, the authority of the credit rating agencies, the use of advanced international credit rating technology, in accordance with strict procedures, the assessed business Credit status of a scientific, reasonable and fair evaluation, to determine their credit rating, and through the issuance of "corporate credit identification certificate" and "corporate credit code" to be a public system. In the era of big data, enterprise credit data volume expands indefinitely, chain indefinitely, it broke the past financial statements as the core of the traditional credit evaluation thinking, formed a "big data platform" to solve the problem of enterprise credit evaluation.

\section{CONCLUSION}

At present, local enterprises credit information database has been established, and credit information of bank credit and government credit are collected. After years of continuous accumulation and information expansion, the enterprise credit information database has the rudiment of enterprise database. In the next step, we should establish and improve the system of enterprise big data and information mining technology to form strong information integration, management, processing and service capabilities. At the same time, the development of Chinese enterprise credit loss brought about by the serious restriction, therefore, strengthen enterprise credit management, establish and perfect enterprise credit system, to foster the healthy and orderly market economy, create a fair competition market environment is also very important. With big data technology matures, we fully development and utilization of big data technology, first from the enterprise credit system construction as the starting point, and gradually build up the government, industry, and personal credit information sharing platform, and finally build a public service as the core of "one network four platforms", namely the Internet under the government, enterprise, industry and the individual credit data platform, four platforms mutual fusion and mutual cooperation, mutual support, complete social credit system.

\section{REFERENCES}

[1] Zipei $\mathrm{Xu}$. The historical reality and future of big data revolution (in Chinese) [M] Beijing: China Citic Press, 2014:85-86

[2] Fang Hu. Analysis on the construction of credit system of small and medium-sized enterprises in China(in Chinese)[D]. Minnan Normal University, 2013.

[3] Ying Chen. Research on the construction of enterprise credit system under big data technology -- taking the construction of enterprise credit data platform as an example (in Chinese) [J]. Contemporary Economy, 2015 (23): 14-17.

[4] Rong Liu, Linlin Cui. Application of big data technology in the construction of mid-and small-scale enterprise credit system (in Chinese) [J]. Credit, 2015 (4): 40-43.

[5] Nan Jia, Guoshun Liu. Construction plan of enterprise credit system under big data era (in Chinese) [J]. Economic Aspect, 2017 (2): 40-44.

[6] Yutao Chen. Problems and Suggestions in the construction of enterprise credit system -- based on the regulatory perspective of industrial and commercial administration department (in Chinese) [J]. China Market Regulatory Research, 2016 (5): 61-64.

[7] Zhe Fan. Construction and credit rating of insurance enterprise credit system. Financial theory and practice (in Chinese), 2015 (12): 94-103.

[8] Hong Zhu. Research on the construction of private enterprise credit system (in Chinese) [J]. China Business Management Research, 2013.

[9] Hui Zeng. Research on enterprise credit system and construction of credit information management platform (in Chinese) [D]. Master Thesis of Dalian Maritime University, 2012.

[10] Dan Li, Wang Hongyan. Problems and suggestions in the construction of credit information system--thinking on the basis of database construction, etc. (in Chinese) [J]. Credit, 2016 (7): 39-41. 